Д. А. Кононович, С. А. Голякевич, С. Е. Арико, С. П. Мохов

Белорусский государственный технологический университет

\title{
АНАЛИЗ ЭФФЕКТИВНОСТИ ПРИМЕНЕНИЯ РАЗЛИЧНЫХ БАЗОВЫХ ШАССИ В ЗАВИСИМОСТИ ОТ МЕСТА УСТАНОВКИ ТЕХНОЛОГИЧЕСКОГО ОБОРУДОВАНИЯ ДЛЯ СБОРА ЛЕСОСЕЧНЫХ ОТХОДОВ
}

В статье представлена сравнительная оценка эффективности эксплуатации базовых шасси и выбора места установки технологического оборудования для сбора лесосечных отходов. Сравнительная оценка эффективности эксплуатации выполнялась на основании удельного энергетического потенциала производительностей. Оценка эффективности эксплуатации базовых шасси производилась в соответствии с их передаточным отношением трансмиссии в зависимости от выбора передач и варианта места установки технологического оборудования для сбора лесосечных отходов при работе на грунтах различных типов. Рассмотрены варианты компоновки базового шасси и технологического оборудования при волочении пачки лесосечных отходов в зависимости от ее объема при работе с понижающим редуктором или без него с учетом грунтов разных типов. Определены основные критерии, влияющие на увеличение эффективности эксплуатации базовых шасси с технологическим оборудованием в зависимости от типа грунтов. Выполнен анализ эффективности эксплуатации машин для сбора лесосечных отходов при проведении технологических операций с изменением скоростных режимов работы в зависимости от базового шасси, типа грунтов, работы с понижающим редуктором или без понижающего редуктора, места установки технологического оборудования.

Ключевые слова: эффективность, базовое шасси, лесосечные отходы, технологическое оборудование.

Для цитирования: Анализ эффективности применения различных базовых шасси в зависимости от места установки технологического оборудования для сбора лесосечных отходов / Д. А. Кононович [и др.] // Труды БГТУ. Сер. 1, Лесное хоз-во, природопользование и перераб. возобновляемых ресурсов. 2021. № 1 (252). С. 105-112.

\section{A. Kononovich, S. A. Golyakevich, S. Ye. Ariko, S. P. Mokhov \\ Belarusian State Technological University}

\section{ANALYSIS OF THE EFFECTIVENESS OF THE USE OF VARIOUS BASE CHASSIS DEPENDING ON THE PLACE OF INSTALLATION OF TECHNOLOGICAL EQUIPMENT FOR COLLECTING LOGGING WASTE}

The article presents the comparative efficiency of the base chassis operation and the choice of the location for the installation of technological equipment for collecting logging waste. A comparative assessment of the operational efficiency was carried out on the basis of the specific energy potential of the capacities. Evaluation of the operating efficiency of the base chassis was carried out during the operation of various types of soils in accordance with their gear ratio of the transmission, depending on the choice of gears and options for installing technological equipment for collecting logging waste. The options for the layout of the base chassis and technological equipment when dragging a pack of logging waste are considered, depending on the volume, taking into account the work on types of soil when working with a reduction gear or without it. The main criteria affecting the increase in the operational efficiency of the base chassis with technological equipment, depending on the type of soil, have been determined. The analysis of the efficiency of operation of machines for collecting felling waste when performing technological operations with a change in speed modes of operation, depending on the base chassis, type of soil, work with or without a reduction gear, the place of installation of technological equipment, has been carried out.

Key words: efficiency, basic chassis, logging waste, technological equipment.

For citation: Kononovich D. A., Golyakevich S. A., Ariko S. Ye., Mokhov S. P. Analysis of the effectiveness of the use of various base chassis depending on the place of installation of technological equipment for collecting logging waste. Proceedings of BSTU, issue 1, Forestry. Nature Management. Proccessing of Renewable Resources, 2021, no. 1 (252), pp. 105-112 (In Russian). 
Введение. Эффективность работы машины для сбора лесосечных отходов оценивается для определения наиболее производительного варианта с учетом выбора базового шасси, места установки технологического оборудования, типа грунта, объема пачки, передаточного отношения трансмиссии, тяговых и сцепных свойств. Эффективность работы машины для сбора лесосечных отходов характеризуется показателями времени на выполнение операций и энергозатратами на их проведение. В качестве интегрального показателя этих характеристик была использована функция удельного энергетического потенциала производительности, который определялся как отношение КПД ко времени цикла [1-3].

Основная часть. При рассмотрении процесса сбора лесосечных отходов с одной пасеки с длиной формирования пачки 12 м по тяговым и сцепным свойствам установлено, что наибольшая эффективность по загрузке оборудования, находящегося на переднем брусе трактора Л82.2, возникает при волочении пачки лесосечных отходов объемом от 1 до $5 \mathrm{~m}^{3}$ и движении базового трактора по грунту I типа с понижающим редуктором (рис. 1).

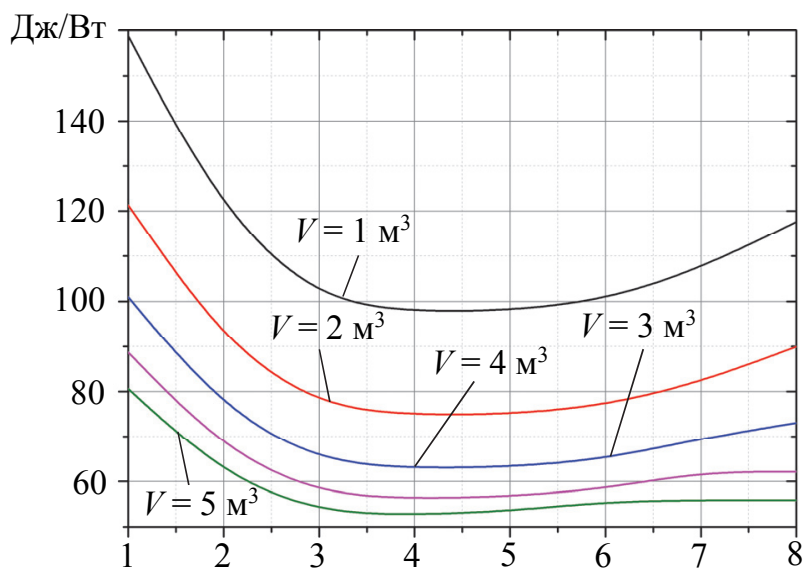

Рис. 1. Эффективность загрузки оборудования для сбора лесосечных отходов в зависимости от выбора передачи базового трактора Л82.2 и волочения пачки по грунту I типа с понижающим редуктором и установкой оборудования на переднем брусе трактора

Так, при волочении пачки до $1 \mathrm{~m}^{3}$ наибольшая эффективность загрузки оборудования достигается при выполнении операции на 4-й и 5-й передачах, для чего требуется 97,7 Дж/Вт. Применение передач выше приводит к снижению эффективности ввиду невозможности максимальной реализации скорости движения. Наибольшая эффективность загрузки при волочении пачки лесосечных отходов объемом 2-4 $\mathrm{m}^{3}$ достигается на 4 передаче. Увеличение объема пачки до $5 \mathrm{~m}^{3}$ приводит к увеличению загрузки технологического оборудования при движении на 3-й передаче и затрачивается 53,1 Дж/Вт. Волочение такого объема невозможно при движении на 6-й и 8-й передачах ввиду низких тяговых свойств базового трактора. Однако использование передач, которые реализуют наибольшую эффективность, не всегда является целесообразным. Это связано с высокими скоростями движения базового трактора - 4,5-5,8 км/ч. Выполнение операции сбора с такой скоростью приводит к высоким динамическим нагрузкам на узлы, агрегаты и оператора. В связи с этим целесообразно применять передачи ниже, развивающие скорости движения до 3,5 км/ч [4].

Движение с понижающим редуктором и без понижающего редуктора по грунтам II типа не имеет существенных отличий. В обоих случаях невозможно волочение пачки лесосечных отходов объемом свыше $2 \mathrm{~m}^{3}$ в связи низкими тяговыми и сцепными свойствами. Наибольшая эффективность загрузки оборудования с понижающим редуктором достигается на 3-й передаче при волочении пачки лесосечных отходов объемом до $1 \mathrm{~m}^{3}$, а без понижающего редуктора на 2-й передаче. Волочение $2 \mathrm{~m}^{3}$ с понижающим редуктором наиболее эффективно осуществлять на 2-й передаче, а без понижающего редуктора на 1-й передаче, так как включение передачи выше приводит к буксованию сцепления [5-7].

В случае формирования пачки лесосечных отходов без включения понижающего редуктора эффективность загрузки оборудования снижается (рис. 2).

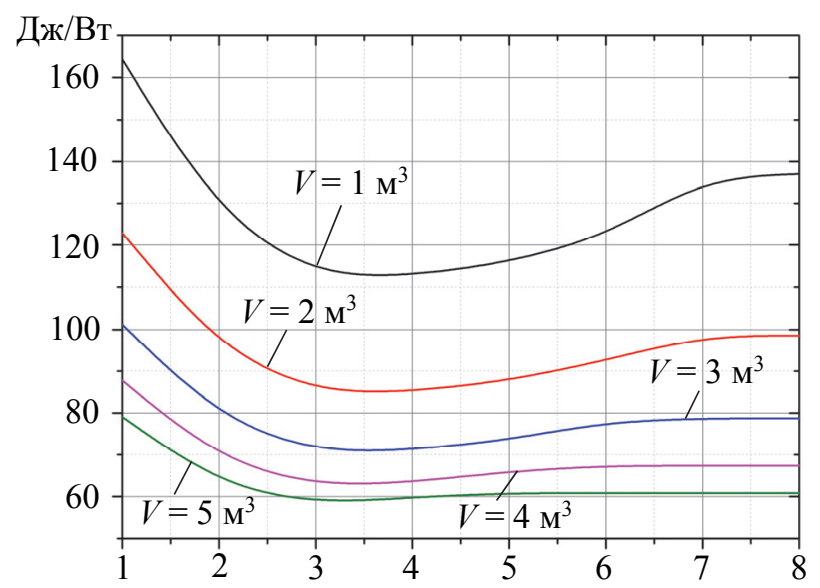

Рис. 2. Эффективность загрузки оборудования для сбора лесосечных отходов в зависимости от выбора передачи базового трактора Л82.2 и волочения пачки по грунту I типа без понижающего редуктора и установкой оборудования на переднем брусе трактора

Установлено, что применение базового трактора Л82.2 на сборе лесосечных отходов без включения понижающего редуктора приводит к снижению 
эффективности загрузки по сравнению с включенным редуктором. Это связано со снижением крутящего момента и скорости движения при выполнении операции. При волочении пачки объемом $5 \mathrm{~m}^{3}$ эффективность загрузки снижается до $10 \%$ и составляет 58,27 Дж/Вт. Также следует отметить, что работа без понижающего редуктора приводит к снижению тяговых свойств и буксование сцепления происходит раньше. При волочении пачки объемом 1-4 м ${ }^{3}$ наиболее эффективно осуществлять сбор на 3-й передаче, а буксование сцепления будет происходить с 4-й по 8-ю передачу. С увеличением объема лесосечных отходов буксование сцепления будет наблюдаться на передачах ниже.

При установлении технологическое оборудования на задней гидравлической навеске Л82.2 и работе с понижающим редуктором эффективность загрузки оборудования увеличивается до $19,3 \%$. Это связано с меньшей массой оборудования, так как отсутствует навесная система для установки технологического оборудования на задней гидравлической навеске, и применением двух передач заднего хода. В случае работы без включения понижающего редуктора эффективность загрузки падает до 19,7\% при волочении пачки лесосечных отходов объемом $5 \mathrm{~m}^{3}$.

При работе на грунтах II типа и установке технологического оборудования на задней гидравлической навеске с включенным понижающим редуктором при волочении пачки лесосечных отходов до $2 \mathrm{~m}^{3}$ эффективность загрузки оборудования падает на $32,22 \%$. В случае работы без включения понижающего редуктора и установке технологического оборудования на задней гидравлической навеске эффективность загрузки падает на $29,75 \%$. Стоит отметить, что максимально возможный объем лесосечных отходов при волочении лесосечных отходов с включенным понижающим редуктором составляет $2 \mathrm{~m}^{3}$. Волочение пачки объемом $2 \mathrm{~m}^{3}$ без включения понижающего редуктора и установке оборудования на задней гидравлической навеске происходит с буксованием сцепления. Волочение пачки объемом свыше $2 \mathrm{~m}^{3}$ невозможно по причине низких тяговых и сцепных свойств.

При использовании в качестве базового трактора Л1221 на сборе лесосечных отходов показатели эффективности эксплуатации оборудования с установленным оборудованием на переднем брусе трактора представлены на рис. 3 .

Применение базового трактора большей мощности на сборе лесосечных отходов не оказывает влияния на увеличение эффективности загрузки оборудования, а наоборот, снижает ее. Это связано с технологическими особенностями при формировании вала, а именно с коротким расстоянием прохождения при наборе пачки лесосечных отходов [8]. Так, при волочении пачки лесосечных отходов объемом $5 \mathrm{~m}^{3}$ эффективность эксплуатации оборудования составит 61,04 Дж/Вт, что ниже на $14 \%$ по сравнению с применением базового трактора Л82.2 с понижающим редуктором и на $4,54 \%$ без редуктора. Отличительной особенностью данного базового трактора является наличие четырехдиапазонной коробки в трансмиссии. Это позволяет применять более высокую передачу без существенного падения эффективности загрузки, что приводит к снижению времени рабочего цикла сбора лесосечных отходов за счет увеличения скорости.

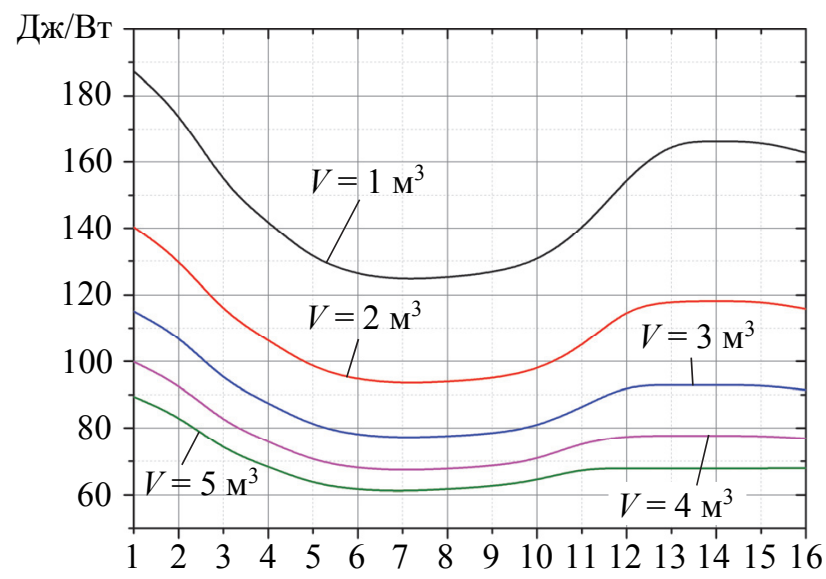

Рис. 3. Эффективность загрузки оборудования для сбора лесосечных отходов в зависимости от выбора передачи базового трактора Л1221 с установкой оборудования на переднем брусе трактора и волочения пачки по грунту I типа

На грунтах II типа наибольшая эффективность загрузки оборудования достигается при волочении пачки лесосечных отходов объемом до $2 \mathrm{~m}^{3}$, а эксплуатационная эффективность в таком случае составляет 181,38 Дж/Вт при работе на 4-5-й передачах базового шасси Л1221. При волочении $1 \mathrm{~m}^{3}$ наибольшая эффективность достигается при работе на 6-й передаче. В таком случае движение базового трактора ограничено при волочении пачки лесосечных отходов свыше $3 \mathrm{~m}^{3}$. Волочение пачки объемом $3 \mathrm{~m}^{3}$ осуществляется с буксованием сцепления.

Эффективность загрузки технологического оборудования на задней гидравлической навеске базового трактора Л1221 при работе на грунте I типа представлена на рис. 4.

Эффективность загрузки оборудования при установке его на задней гидравлической навеске базового трактора Л1221 и осуществлении сбора лесосечных отходов на почве I типа составляет 82,84 Дж/Вт при волочении пачки объемом $5 \mathrm{~m}^{3}$ и движении на 3-й передаче заднего хода. Буксование сцепления в таком случае будет происходить при включении 6-й передачи и выше [9-11]. 
При волочении пачки объемом 1-4 м ${ }^{3}$ наибольшая эффективность загрузки оборудования достигается на 3-4-й передачах. В случае волочения пачки лесосечных отходов объемом до $1 \mathrm{~m}^{3}$ по грунту I типа эффективность применения в качестве базового трактора Л1221 ниже в 2,09 раза по сравнению с Л82.2 при работе с пониженным редуктором и 1,33 раза без редуктора. Так, при волочении пачки лесосечных отходов объемом $5 \mathrm{~m}^{3}$ эффективность эксплуатации оборудования с базовым трактором Л1221 ниже в 1,87 раза по сравнению с применением базового трактора Л82.2 с понижающим редуктором и в 1,23 раза ниже без редуктора. Применение понижающего редуктора позволяет снизить вероятность буксования сцепления за счет подведения более высокого крутящего момента при выполнении операции сбора лесосечных отходов. Однако применение понижающего редуктора приводит к увеличению времени, затрачиваемого на такие операции, за счет снижения скорости движения базового шасси. Поэтому понижающий редуктор целесообразно применять в случае эксплуатации такой машины на грунтах с низкой несущей способностью, волочения пачек отходов большого объема и т. д.

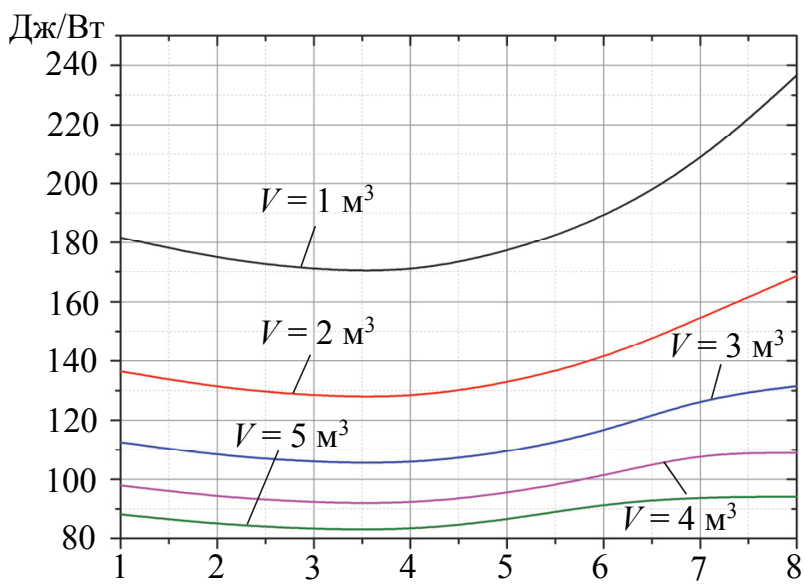

Рис. 4. Эффективность загрузки оборудования для сбора лесосечных отходов в зависимости от выбора передачи базового трактора Л1221

и волочения пачки по грунту I типа с установкой оборудования на его задней гидравлической навеске

Установлено, что движение по грунту II типа невозможно при волочении пачки лесосечных отходов объемом свыше $2 \mathrm{~m}^{3}$ (рис. 5).

Это связано с низкими тяговыми и сцепными свойствами базового трактора. Так, при волочении пачки объемом $1 \mathrm{~m}^{3}$ эффективность загрузки оборудования достигает 281 Дж/Вт при движении на 3-й передаче. Передачи выше приводят к снижению эффективности и буксованию сцепления. При волочении пачки объемом $2 \mathrm{~m}^{3}$ эффективность возрастает до 221,4 Дж/Вт при движении на 2-й передаче. Волочение пачки лесосечных отходов объемом $3 \mathrm{~m}^{3}$ приводит к буксованию сцепления на любой передаче, что свидетельствует о недостаточности тяговых свойств для перемещения.

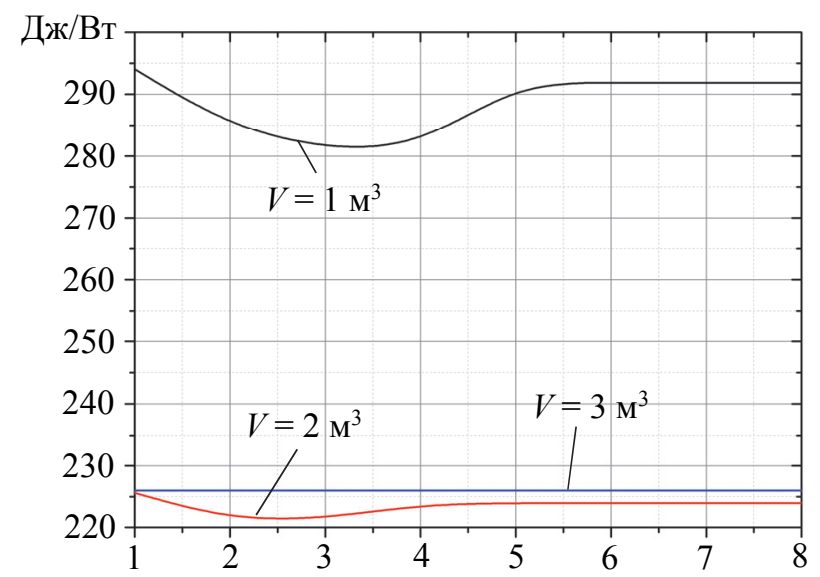

Рис. 5. Эффективность загрузки оборудования для сбора лесосечных отходов в зависимости от выбора передачи базового трактора Л1221 и волочения пачки по грунту II типа с установкой оборудования на его задней гидравлической навеске

В случае применения базового трактора Л82.2 эффективность загрузки оборудования на почвах II типа будет незначительно выше, чем на задней гидравлической навеске, как с понижающим, так и без понижающего редуктора.

Однако общая эффективность загрузки оборудования с применением базовых тракторов Л82.2 и Л1221 является низкой. Установлено, что холостой ход в технологии сбора лесосечных отходов снижает эффективность загрузки оборудования в 1,3 раза. Соответственно, повышения эффективности загрузки оборудования можно достигнуть путем изменения конструкции оборудования, применения базового трактора меньшей массой или изменения технологии сбора лесосечных отходов.

Наибольшая эффективность при применении на грунтах I типа в качестве базового трактора МТ3-320 и установкой технологического оборудования на его переднем брусе достигается при работе на 4-й передаче без понижающего редуктора (рис. 6) и составляет 99,03 Дж/Вт при волочении $2 \mathrm{~m}^{3}$ лесосечных отходов и на 7-й передаче с применением понижающего редуктора (рис. 7). Эффективность эксплуатации МТ3-320 без понижающего редуктора с установленным технологическим оборудованием на переднем брусе трактора при волочении пачки объемом $2 \mathrm{~m}^{3}$ ниже на $14,44 \%$ по сравнению с Л82.2 при таких же условиях, а при использовании понижающего редуктора эффективность падает до 24,25\%. Это связано с очень большим передаточным числом понижающего редуктора у МТЗ-320, что приводит к большой затрате времени при выполнении технологических операций. 


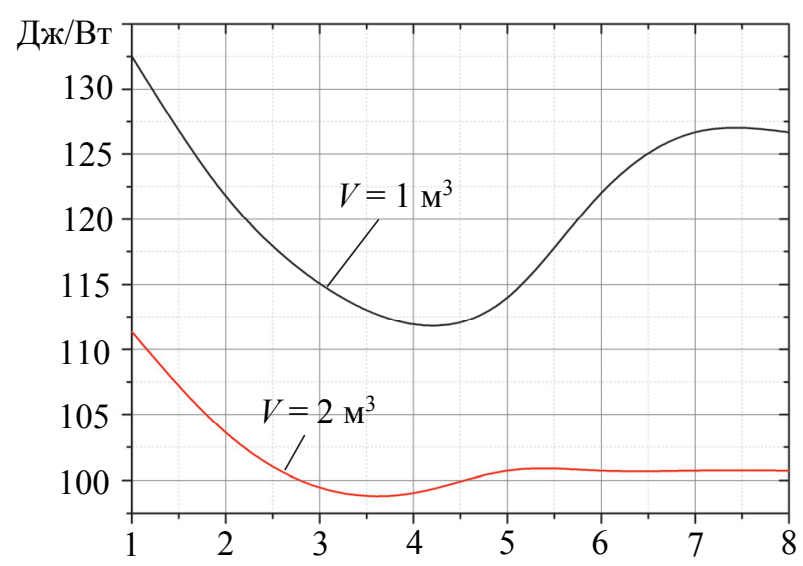

Рис. 6. Эффективность загрузки оборудования для сбора лесосечных отходов в зависимости от выбора передачи базового трактора МТЗ-320 без понижающего редуктора и волочения пачки по грунту I типа с установкой оборудования на переднем брусе трактора

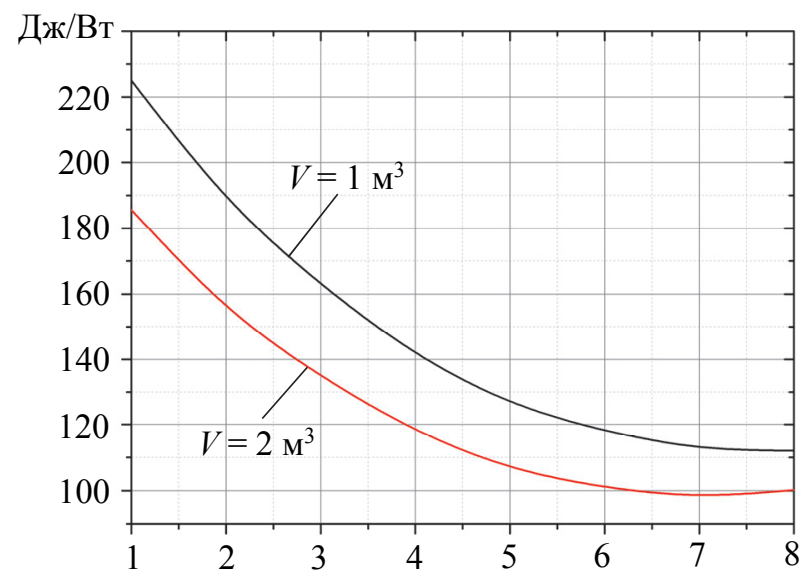

Рис. 7. Эффективность загрузки оборудования для сбора лесосечных отходов в зависимости от выбора передачи базового трактора МТЗ-320 с понижающим редуктором и волочения пачки по грунту I типа с установкой оборудования на переднем брусе трактора

Эффективность эксплуатации МТЗ-320 без понижающего редуктора и волочении пачки отходов объемом 2 м $^{3}$ по сравнению с Л1221 при аналогичных условиях ниже на $6,08 \%$, а с понижающим редуктором меньше на 5,69\%. Это связано с тем, что базовое шасси Л1221 не полностью реализует свой потенциал при волочении пачки объемом $2 \mathrm{~m}^{3}$, когда наибольшая эффективность загрузки оборудования достигается при волочении $5 \mathrm{~m}^{3}$ лесосечных отходов.

При работе на грунтах I типа базового шасси МТЗ-320 с установкой оборудования на задней гидравлической навеске эффективность его загрузки представлена на рис. 8 и рис. 9.

При применении на грунтах I типа в качестве базового трактора МТЗ-320 с установкой технологического оборудования на его задней гидравлической навеске наибольшая эффективность достигается при работе на 3-й передаче заднего хода без понижающего редуктора и составляет 73,67 Дж/Вт при волочении $1 \mathrm{~m}^{3}$ лесосечных отходов и на 4-й передаче заднего хода с применением понижающего редуктора. Стоит отметить, что волочение пачки объемом $2 \mathrm{~m}^{3}$ без понижающего редуктора невозможно ввиду низких тяговых свойств базового шасси [12-14].

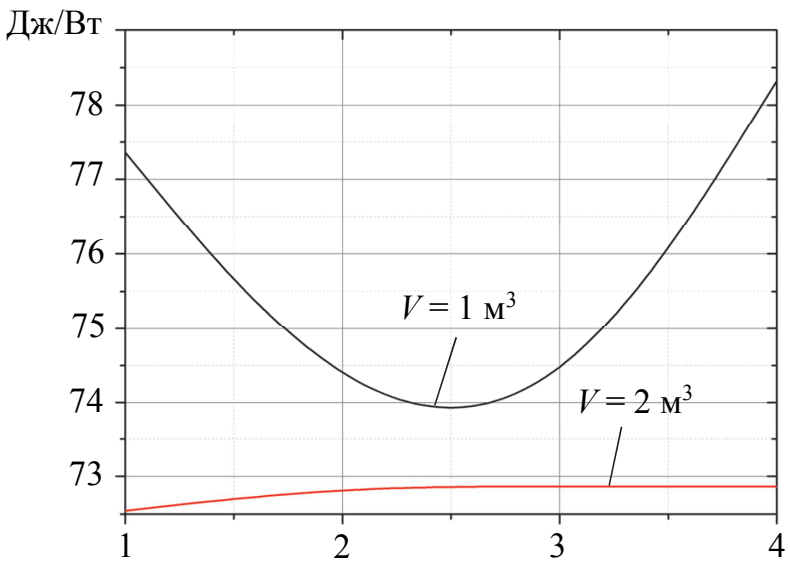

Рис. 8. Эффективность загрузки оборудования для сбора лесосечных отходов в зависимости от выбора передачи базового трактора МТЗ-320 без понижающего редуктора и волочения пачки по грунту I типа с установкой оборудования на задней гидравлической навеске трактора

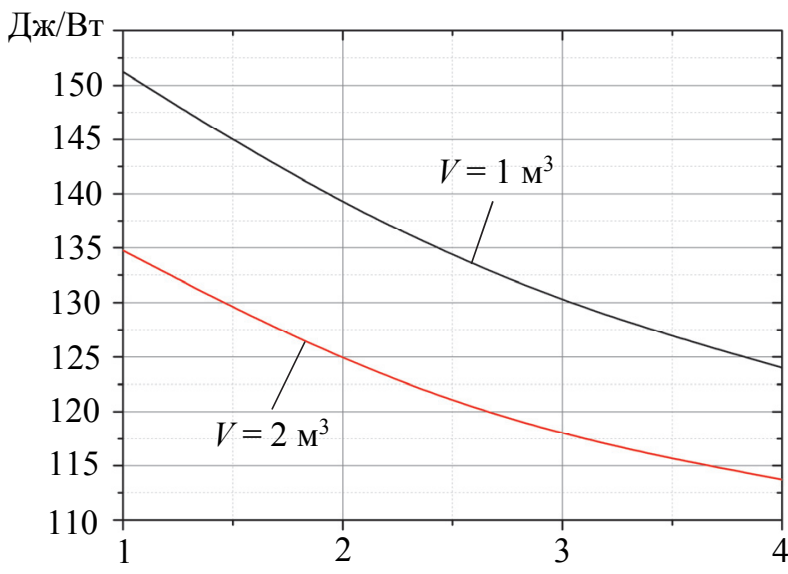

Рис. 9. Эффективность загрузки оборудования для сбора лесосечных отходов в зависимости от выбора передачи базового трактора МТЗ-320 с понижающим редуктором и волочения пачки по грунту I типа с установкой оборудования на задней гидравлической навеске трактора

При сравнении применения базового шасси установлено, что эффективность МТЗ-320 с установкой оборудования на задней гидравлической навеске и работе без редуктора на грунтах I типа выше на 42,36\% по сравнению с Л82.2 и на 
$56,63 \%$ по сравнению Л1221 в таких же условиях. Однако волочение $1 \mathrm{~m}^{3}$ лесосечных отходов для МТЗ-320 является максимальной эффективной загрузкой, а для Л 82.2 и Л1221 - минимальной, и поэтому применение базового шасси МТЗ-320 нецелесообразно в природно-производственных условиях с волочением пачки лесосечных отходов выше $1 \mathrm{~m}^{3}$.

Применение понижающего редуктора в базовом шасси МТЗ-320 приводит к снижению его эффективности на $83,23 \%$ по сравнению с Л 82.2 и увеличению эффективности на $10,85 \%$ в отличие от Л1221. Это связано с тем, что понижающий редуктор в МТЗ-320 имеет большое передаточное число, что снижает рабочую скорость и увеличивает затрачиваемое время на выполнение технологических операций, к тому же в данных условиях базовое шасси МТЗ-320 с оборудованием максимально загружено, а Л82.2, наоборот, минимально [15]. Увеличение эффективности по сравнению с Л1221 связано все с той же загрузкой оборудования и временем, затрачиваемым на выполнение операций сбора. Эффективность Л1221 заключатся в больших загрузочных диапазонах, чем у МТЗ-320.

Заключение. В процессе проведения исследований по эффективности загрузки оборудования при выборе базового шасси установлено, что наибольшая эффективность достигается при установке технологического оборудования на задней гидравлической навеске базового шасси Л82.2 при работе на грунтах I типа с понижающим редуктором. Установка технологического оборудования на переднем брусе трактора приводит к снижению эффективности до $16,13 \%$ загрузки оборудования, но облегчает работу оператора и обеспечивает равномерное распределение реакций при условии работы с понижающим редуктором. Эксплуатация базового шасси без понижающего редуктора приводит к снижению эффективности загрузки оборудования на 9,71\% при установке его на переднем брусе трактора и на $36,74 \%$ - на задней гидравлической навеске.

При работе на грунтах II типа и установке технологического оборудования на переднем брусе трактора эффективность загрузки оборудования с понижающим редуктором выше на 4\%, чем без редуктора. При установке на задней гидравлической навеске эффективность загрузки падает на 21-25\% в зависимости от работы с редуктором или без него. При применении в качестве базового шасси Л1221 и установке технологического оборудования на переднем брусе трактора эффективность эксплуатации оборудования падает на $13,81 \%$ по сравнению с базовым трактором Л82.2 с понижающим редуктором и на $4,53 \%$ без редуктора. В случае установки оборудования на задней гидравлической навеске Л1221 эффективность загрузки оборудования снижается в 1,87 раза по сравнению с работой Л 82.2 с понижающим редуктором и на 1,18 раза без редуктора. На грунтах II типа работа базового шасси Л1221 имеет эффективность загрузки ниже в отличие от Л82.2 при установке технологического оборудования на переднем брусе трактора на $12,2 \%$ с понижающим редуктором и на $8,6 \%$ без редуктора. Установка оборудования на задней гидравлической навеске приводит к снижению эффективности на $2,15 \%$ с понижающим редуктором и $2,48 \%$ без редуктора.

Эффективность эксплуатации МТЗ-320 на сборе без понижающего редуктора с установленным технологическим оборудованием на переднем брусе трактора при волочении $2 \mathrm{~m}^{3}$ лесосечных отходов ниже на $14,44 \%$ по сравнению с Л82.2 в таких же условиях, а при использовании понижающего редуктора эффективность падает до $24,25 \%$. Это связано с очень большим передаточным числом понижающего редуктора у МТ3-320, что приводит к большой затрате времени при выполнении технологических операций. Эффективность эксплуатации МТЗ-320 без понижающего редуктора и волочении $2 \mathrm{~m}^{3}$ лесосечных отходов при сравнении с Л1221 в таких же условиях ниже на $6,08 \%$, а с понижающим редуктором - на $5,69 \%$. Это связано с тем, что базовое шасси Л1221 неполностью реализует свой потенциал при волочении пачки объемом $2 \mathrm{~m}^{3}$, наибольшая же эффективность загрузки оборудования достигается при волочении $5 \mathrm{~m}^{3}$. Стоит отметить, что эффективности загрузки оборудования, установленного на переднем брусе трактора МТЗ-320 при его работе с понижающим редуктором и без редуктора, на грунтах $I$ типа практически идентичны, но достигаются они на разных передачах.

\section{Список литературы}

1. Жуков А. В. Теория лесных машин. Минск: БГТУ, 2001. 640 с.

2. Голякевич С. А., Гороновский А. Р., Мохов С. П. Методика оценки технических характеристик форвардеров на стадии проектирования // Труды БГТУ. 2016. № 2: Лесная и деревообраб. пром-сть. C. $15-19$.

3. Исаченков В. С., Симанович В. А. Обоснование параметров прицепного технологического оборудования колесных трелевочных машин // Труды БГТУ. 2016. № 2: Лесная и деревообраб. пром-сть. C. 23-27.

4. Анализ конструктивных особенностей машин для сбора лесосечных отходов / Д. А. Кононович [и др.] // Труды БГТУ. 2016. № 2: Лесная и деревообраб. пром-сть. С. 31-35. 
5. Голякевич С. А., Гороновский А. Р. Комплексная техническая оценка потребительских качеств лесных машин // Труды БГТУ. 2015. № 2: Лесная и деревообраб. пром-сть. С. 67-70.

6. Лой В. Н., Германович А. О. Моделирование работы самоходной рубильной машины с автономным двигателем // Труды БГТУ. 2013. № 2: Лесная и деревообраб. пром-сть. С. 18-21.

7. Голякевич С. А. Анализ эксплуатационных режимов работы многооперационных лесозаготовительных машин // Труды БГТУ. 2013. № 2: Лесная и деревообраб. пром-сть. С. 72-78.

8. Арико С. Е. Математическая модель работы харвестерной машины 4К4 // Труды БГТУ. Сер. II, Лесная и деревообраб. пром-сть. 2010. Вып. XVIII. С. 113-117.

9. Симанович В. А. Оценка динамического нагружения колесных лесных машин на эксплуатационных режимах работы // Труды БГТУ. 2010. Сер. II, Лесная и деревообраб. пром-сть. 2010. Вып. XVIII. C. $122-125$.

10. Голякевич С. А. Применение систем адаптивного управления для повышения реализации энергетического потенциала харвестерами // Труды БГТУ. Сер. 1, Лесное хоз-во, природопользование и перераб. возобновляемых ресурсов. 2017. № 2. С. 238-244.

11. Голякевич С. А., Гороновский А. Р. Нагруженность несущей конструкции харвестера при выполнении технологических операций // Труды БГТУ. 2011. № 2: Лесная и деревообраб. пром-сть. C. $27-30$.

12. Симанович В. А., Пищов М. Н., Смеян А. И. Особенности эксплуатационных режимов нагружения лесных агрегатных машин // Труды БГТУ. Сер. 1, Лесная и деревообраб. пром-сть. 2007. Вып. XV. C. 77-78.

13. Симанович В. А., Исаченков В. С., Бобрович В. А. Оценка динамической нагруженности трелевочной системы «колесный трактор - пачка деревьев» // Труды БГТУ. Сер. II, Лесная и деревообраб. пром-сть. 2007. Вып. XV. С. 74-76.

14. Пищов С. Н. Математическая модель колебаний форвардера 6 К6 повышенной грузоподъемности // Труды БГТУ. Сер. II, Лесная и деревообраб. пром-сть. 2007. Вып. XV. С. 52-55.

15. Исаченков В. С., Симанович В. А. Математическая модель колесной трелевочной машины // Труды БГТУ. 2011. №. 2, Лесная и деревообраб. пром-сть. С. 75-81.

\section{References}

1. Zhukov A. V. Teoriya lesnykh mashin [The theory of forest machines]. Minsk, BGTU Publ., 2001. 640 p. (In Russian).

2. Golyakevich S. A., Goronovskiy A. R. Method estimation specifications forwarders on the design stage. Trudy BGTU [Proceedings of BSTU], 2016, no. 2: Forest and Woodworking Industry, pp. 15-19 (In Russian).

3. Isachenkov V. S., Simanovich V. A. Substantiation of the parameters of tow technology equipment wheeled skidders. Trudy BGTU [Proceedings of BSTU], 2016, no. 2: Forest and Woodworking Industry, pp. 23-27 (In Russian).

4. Kononovich D. A., Mokhov S. P., Simanovich V. A., Ariko S. Ye. Analysis of structural features of machines for collection forest residues. Trudy BGTU [Proceedings of BSTU], 2016, no. 2: Forest and Woodworking Industry, pp. 31-35 (In Russian).

5. Golyakevich S. A., Goronovskiy A. R. Integrated technical assessment of the consumer qualities of forest machines. Trudy BGTU [Proceedings of BSTU], 2015, no. 2: Forest and Woodworking Industry, pp. 67-70 (In Russian).

6. Loy V. N., Germanovich A. O. Modeling the work of a self-propelled chipper with an autonomous engine. Trudy BGTU [Proceedings of BSTU], 2013, no. 2: Forest and Woodworking Industry, pp. 18-21 (In Russian).

7. Golyakevich S. A. Modeling the work of a self-propelled chipper with an autonomous engine. Trudy $B G T U$ [Proceedings of BSTU], 2013, no. 2: Forest and Woodworking Industry, pp. 72-78 (In Russian).

8. Ariko S. Ye. The mathematical model of the harvester 4W4. Trudy BGTU [Proceedings of BSTU], series II, Forest and Woodworking Industry, 2010, issue XVIII, pp. 113-117 (In Russian).

9. Simanovich V. A. Evaluation of the dynamic loading of wheeled forest machines at operational operating modes. Trudy BGTU [Proceedings of BSTU], series II, Forest and Woodworking Industry, 2010, issue XVIII, pp. 122-125 (In Russian).

10. Golyakevich S. A. Application of adaptive control systems to increase the realization of energy potential of harvesters. Trudy BGTU [Proceedings of BSTU], issue 1, Forestry, Nature Management and Renewable Resources Processing, 2017, no. 2, pp. 238-244 (In Russian).

11. Golyakevich S. A., Goronovskiy A. R. The load bearing structure of the harvester during technological operations. Trudy BGTU [Proceedings of BSTU], 2011, no. 2: Forest and Woodworking Industry, pp. 27-30 (In Russian). 
12. Simanovich V. A., Pishchov M. N., Smeyan A. I. Features of operational modes of loading of forest modular machines. Trudy BGTU [Proceedings of BSTU], series 2, Forest and Woodworking Industry, 2007, issue XV, pp. 77-78 (In Russian).

13. Simanovich V. A., Isachenkov V. S., Bobrovich V. A. Evaluation of the dynamic loading of the skidding system "wheeled tractor - a pack of trees". Trudy BGTU [Proceedings of BSTU], series 2, Forest and Woodworking Industry, 2007, issue XV pp. 74-76 (In Russian).

14. Pishchov S. N. Mathematical model of oscillations of a forwarder 6W6 of increased carrying capacity. Trudy BGTU [Proceedings of BSTU], series 2, Forest and Woodworking Industry, 2007, issue XV, pp. 52-55 (In Russian).

15. Isachenkov V. S., Simanovich V. A. Mathematical model of a skidder. Trudy BGTU [Proceedings of BSTU], 2011, no. 2: Forest and Woodworking Industry, pp. 75-81 (In Russian).

\section{Информация об авторах}

Кононович Денис Александрович - ассистент кафедры лесных машин, дорог и технологий лесопромышленного производства. Белорусский государственный технологический университет (220006, г. Минск, ул. Свердлова, 13а, Республика Беларусь). E-mail: denkon_92@mail.ru

Голякевич Сергей Александрович - кандидат технических наук, доцент кафедры лесных машин, дорог и технологий лесопромышленного производства. Белорусский государственный технологический университет (220006, г. Минск, ул. Свердлова, 13a, Республика Беларусь). E-mail: gsa@belstu.by

Арико Сергей Евгеньевич - кандидат технических наук, доцент кафедры лесных машин, дорог и технологий лесопромышленного производства. Белорусский государственный технологический университет (220006, г. Минск, ул. Свердлова, 13a, Республика Беларусь). E-mail: sergeyariko@mail.ru

Мохов Сергей Петрович - кандидат технических наук, доцент, заведующий кафедрой лесных машин, дорог и технологий лесопромышленного производства. Белорусский государственный технологический университет (220006, г. Минск, ул. Свердлова, 13a, Республика Беларусь). E-mail: 1mitlz@belstu.by

\section{Information about the authors}

Kononovich Denis Aleksandrovich - Assistant Lecturer, the Department of Logging Machinery, Forest Roads and Timber Production Technology. Belarusian State Technological University (13a, Sverdlova str., 220006, Minsk, Republic of Belarus).E-mail: denkon_92@mail.ru

Golyakevich Sergey Aleksandrovich - PhD (Engineering), Assistant Professor, the Department of Logging Machinery, Forest Roads and Timber Production Technology. Belarusian State Technological University (13a, Sverdlova str., 220006, Minsk, Republic of Belarus). E-mail: gsa@belstu.by

Ariko Sergey Yevgen'evich - PhD (Engineering), Assistant Professor, the Department of Logging Machinery, Forest Roads and Timber Production Technology. Belarusian State Technological University (13a, Sverdlova str., 220006, Minsk, Republic of Belarus). E-mail: sergeyariko@mail.ru

Mokhov Sergey Petrovich - PhD (Engineering), Associate Professor, Head of the Department of Logging Machinery, Forest Roads and Timber Production Technology. Belarusian State Technological University (13a, Sverdlova str., 220006, Minsk, Republic of Belarus).E-mail: 1mitlz@belstu.by 